Conclusion Although a significant proportion of patients on elderly care wards are in the last year of life, there was minimal sharing of ACP information with community services. The 'process' change of including a mandatory ACP section on discharge summaries has not improved outcomes. Future quality improvement will focus on staff engagement and raising awareness of the importance of ACP. We have developed a blended learning programme to support the implementation of routine identification of patient in their last year of life in multi-disciplinary meetings, thereby triggering ACP and communication across organisations.

\section{P-18 ADVANCE CARE PLANNING ACROSS ENGLAND AND WALES}

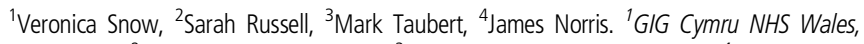
Cardiff, UK; ${ }^{2}$ Hospice UK, London, UK; ${ }^{3}$ Velindre NHS Trust, Cardiff, UK; ${ }^{4}$ Digital Legacy Association, London, UK

10.1136/bmjspcare-2017-hospice.45

Background Last year Byw Nawr commissioned the research and development of a new public facing website. The resource drew on expertise from Dying Matters, Hospice UK, the Digital Legacy Association and a number of healthcare professionals.

Aim The aim of the website is to make Advance Care Planning accessible to the general public though a clear information architecture and videos.

Methods By working collaboratively, a website containing over 10000 words was created in English. It was then translated into Welsh. A small stakeholder group provided ongoing advice and a wider stakeholder group was called upon at the end of the website's build for review.

Results and Conclusion Later this year Byw Nawr will evaluate the impact of the resource. It is hoped that the results will be displayed as a poster or through a presentation at the Hospice UK conference in November.

\section{P-19 HIGHLIGHT 5 - 5 MINUTES TO DELIVER MESSAGES ON PATIENT CARE}

Charles Hyland, Susan Schofield, Paula Powell. Willowbrook Hospice Merseyside, UK

\subsection{6/bmjspcare-2017-hospice.46}

At any one time in a health organisation there are important messages on patient care that staff need to be informed of but disseminating that information such that all staff see and hear those messages and respond appropriately is very challenging. E-mails, team briefs, written policies and procedures may be left unread and even verbal information can be missed by some. HIGHLIGHT 5 describes an initiative developed to improve communication and ensure that as many staff as possible hear important messages about patient care. Each week has a defined topic that can be covered in $5 \mathrm{~min}$ by a member of the clinical staff. The ward manager and practice development nurse plan the topics in advance but all staff can contribute ideas. Examples so far are cost effective prescribing of laxatives, opioid brand prescribing and introduction of a sepsis care bundle. The Highlight topic is delivered at every handover throughout the seven days so all members of staff as far as possible are aware. Feedback is very positive from staff who feel that it is very effective at ensuring important messages are highlighted.

\section{P-20 RELEASING TIME TO CARE - A BOARD AT A GLANCE!}

Augustina Ebiredelu, Edith Simfukwe, Michelle Hatcher, Christine Johnson. Garden House Hospice Care, Letchworth Garden City, UK

\subsection{6/bmjspcare-2017-hospice.47}

Background Devising a new patient information board for the nurses' office was to improve the efficiency of the nurse in charge and reduce time spent on handover. Due to a variety of shift patterns worked on the in-patient unit, handovers became a long and laborious task that would occur up to eight times a day to cater for all the staff starting their shifts at different times including MDT. This in turn meant that the nurse in charge would be spending long periods out of their day handing over the same information to different staff which took them away from being able to carry out patient care and take charge of their shift.

Aim Decrease the time of handovers by having useful information available at a glance and to reduce the risk of delays in (OACC) Outcome Assessment and Complexity Collaboration assessments and relevant tasks being carried out by the designated date.

Method HotBoard company was contacted to devise and design a bespoke information board to meet the requirement of the information necessary to reduce handover times. Between the nursing and medical team, a collaborative effort was made to decide what information was to be included on the board to streamline the handovers. The designers incorporated the hospice care logo and colour scheme to give a unified look and the designs were regularly amended until everyone was satisfied with the information on the board.

Results There has already been a marked improvement in the effectiveness of handovers. There are two handovers which take $30 \mathrm{~min}$ each. Bank staff working short shifts can read the information rather than take a nurse away from caring for patient to carry out handover. Team members can quickly check the board for OACC and dates that assessments are due for patients and this has noticeably reduced the delays in these being completed for patients.

Conclusion We are due to carry out an audit soon to evaluate the time efficiency of the board and how delays have been reduced and hour many hours have been released for nurses to spend with patients per nurse.

\section{P-21 WHAT DOES OUR COMMUNITY KNOW? RESEARCHING PUBLIC PERCEPTIONS TO DIRECT THE FUTURE OF COMMUNICATIONS}

Alice Spearing. St Richard's Hospice, Worcester, UK

\subsection{6/bmjspcare-2017-hospice.48}

Background The hospice has a strategic aim to develop and maintain its profile across the county as an essential charity to support. The messages we communicate to the community forms their understanding of our care. Past communications have been guided by assumptions of what the community does and does not know. Market research was an opportunity to produce evidence on our community's awareness. 